\title{
Pathophysiological Mechanisms of Paradoxical Effect of Acute Poisoning by Synthetic Psychoactive Substances in Combination with Ethanol
}

DOI: $10,17691 / \mathrm{stm} 2018.10 .3 .21$

Received January 20, 2018

N.A. Shchelchkova, PhD, Head of Molecular and Cell Technologies Department,

Central Scientific Research Laboratory ${ }^{1}$; Associate Professor, Department of Neurotechnologies, Institute of Biology and Biomedicine?

A.V. Larchenko, Therapeutist ${ }^{3}$;

S.A. Razgulin, MD, DSc, Head of the Catastrophe Medicine Department ${ }^{1}$;

S.A. Mudrova, MD, Head of the Toxicological Unit3;

M.A. Suvorov, MD, PhD, Associate Professor, Therapeutist ${ }^{3}$;

S.A. Kudryavtsev, MD, PhD, Associate Professor, Therapeutist;

M.V. Lyamkin, MD, PhD, Therapeutist ${ }^{3}$;

Ya.V. Kaurov, MD, DSc, Associate Professor, Therapeutist ${ }^{3}$

${ }^{1}$ Privolzhsky Research Medical University, 10/1 Minin and Pozharsky Square, Nizhny Novgorod, 603005, Russia;

${ }^{2}$ Lobachevsky State University of Nizhni Novgorod, 23 Prospekt Gagarina, Nizhny Novgorod, 603950, Russia;

${ }^{3}$ Municipal Hospital No.33, 54 Prospekt Lenina, Nizhny Novgorod, 603076, Russia

At present, there exists a vital problem of studying pathophysiological mechanisms of acute poisoning and the developing intoxication syndrome caused by taking psychoactive substances by the users, e.g. cathinones, to stimulate pharmacologically the effect of ethyl alcohol. A number of compounds with a narcogenic potential and some medicinal preparations, e.g. imipramine, are referred to the class of synthetic cathinones.

The aim of the investigation was to study the effect of ethyl alcohol on animal behavior and the activity of some enzymes of the liver and the antioxidant system in acute imipramine poisoning.

Materials and Methods. 167 patients of the Toxicological Center with poisoning by synthetic psychoactive substances and ethyl alcohol as well as 70 Wistar rats participated in the study. The animals were divided into 4 groups: those who were injected with physiological solution, imipramine, ethanol, and imipramine in combination with ethanol. Orientation and exploratory behavior of the rats, the activity of the liver and antioxidant system enzymes have been investigated.

Results. It has been established that in acute ethanol and imipramine poisoning, restoration of orientation and exploratory behavior of the rats occurs more rapidly, inhibition of the enzymatic activity of the liver (ethanol dehydrogenase, lactate dehydrogenase) and the antioxidant system is noted but to a less extent than in acute imipramine intoxication.

Key words: body intoxication; psychotropic substances; imipramine; ethanol; rat behavior in poisoning; combination of cathinones with ethanol.

\section{Introduction}

Users' intake of synthetic narcotic psychoactive agents (cathinones) for pharmacological stimulation of small doses of ethyl alcohol is a serious problem of modern toxicology. Their combined use results in formation of specific pathophysiological reactions and pathomorphism of the pathology developing in such cases.

Manifestation of super intensive effect of xenobiotic on the CNS prevails in the clinical picture of acute poisoning by synthetic psychotropic substances. Toxic and metabolic disorders are developing: hypoxia, alterations of the oxidative phosphorylation processes, disbalance in the pro- and antioxidant systems [1].

There is no agreement regarding the combined action of narcotics and ethanol on the body. Some scientists hold the traditional opinion that ethanol enhances toxicity of various psychotropic substances (for example the authors of work [2]), others, on the basis of the analysis of numerous clinical data, try to prove that the course and outcome of such poisoning at blood alcohol concentration up to $3 \mathrm{~g} / \mathrm{L}$ are more favorable compared to intoxication caused by psychotropic agents [3].

There exists a series of analogs to synthetic cathinones, which are produced as medicinal agents

Corresponding author: Natalia A. Shchelchkova, e-mail: n.shchelchkova@mail.ru 
and possess similar properties. Imipramine is just referred to these pharmacological substances. It is a pharmacological preparation of antidepressant group, which have antidepressant, thymoleptic, psychostimulating, and antidysuric action [4].

Imipramine inhibits re-uptake of neuromediator monoamines (noradrenaline, dopamine, serotonin, and others) by presynaptic neuron nerve endings increasing thereby their level in the synaptic cleft and enhancing physiological activity. The degree of manifestation of behavioral depression signs and the level of emotional anxiety after poisoning are known to determine the medication neurotropism. Consumption of imipramine with alcohol, much as in case with synthetic narcotics, is of great interest as the mechanism and consequences of the combined poisoning by psychopharmacological agents with ethanol are poorly studied.

The aim of the investigation was to study the effect of ethyl alcohol on the behavior of animals and the activity of some enzymes of the liver and the antioxidant system in acute imipramine poisoning.

\section{Materials and Methods}

167 patients of the Toxicological Center of the Municipal Hospital No.33 participated at the first stage of the investigation. They were divided into three groups: group $1(n=67)$ included patients with poisoning by various psychoactive substances; group $2(n=51)$ poisoning by ethyl alcohol; group 3 poisoning by synthetic psychoactive substances in combination with ethyl alcohol.

The study complies with the Declaration of Helsinki (2013) and was approved by the Ethics Committee of Privolzhsky Research Medical University. Written informed consent was obtained from every patient.

At the second stage, the work was carried out at the premises of the Central Scientific Research Laboratory of Privolzhsky Research Medical University (Russia). The objects of the investigation were mature male rats of Wistar line weighing 280-300 g $(n=70)$. All manipulations with animals were performed in compliance with Guide for the Care and Use of Laboratory Animals (National Research Council, 2011), the national standard RF GOST 33044-2014 "Principles of Good Laboratory Practice", and the Protection of Vertebrate Animals used for Experimental and other Scientific Purposes (Strasbourg, 2006). The study protocol was approved by the Ethics Committee of Privolzhsky Research Medical University.

To carry out the experiment, four groups of animals were formed: group $1 \quad(n=10)$ were injected with physiological solution (control); group $2(n=10)$ with imipramine; group $3(n=10)$ with ethanol; group $4(n=10)$ with imipramine in combination with ethanol.

Acute ethanol poisoning in animals was induced by intraperitoneal introduction of $33 \%$ solution of ethyl alcohol (ethanol) at a dose of $5 \mathrm{~g} / \mathrm{kg}$ body mass. Imipramine was injected at a rated dose of $\mathrm{LD}_{50}=79 \mathrm{mg} / \mathrm{kg}$ body mass. Combined poisoning was induced by a successive injection of ethanol at a dose of $5 \mathrm{~g} / \mathrm{kg}$ and imipramine 10 min later at a rated dose of $\mathrm{LD}_{50}=79 \mathrm{mg} / \mathrm{kg}$ body mass. Immediately and $12 \mathrm{~h}$ after the recovery of the experimental animals from coma, orientation and exploratory behavior in the open field test was performed according to the standard protocol.

To visualize the animal movements and to process the data obtained, the SMART ver.3.0 program was used. Horizontal and vertical activity, as well as grooming and freezing reactions, were evaluated.

At the third stage of the investigation, the activity of the hepatic and antioxidant system enzymes involved in the formation of intoxication syndrome was studied. 30 remained animals were divided into 3 groups: group 1 , control $(n=10)$ with the introduction of physiological solution; group $2(n=10)$ with imipramine; group $3(n=10)$ with imipramine and ethanol. $12 \mathrm{~h}$ after the recovery from coma, euthanasia of the animals was performed to determine enzyme activity: ethanol dehydrogenase (EDG), lactate dehydrogenase (LDG) in the liver and antioxidant system enzymes in erythrocytes (superoxide dismutase (SOD) and catalase) using standard spectrophotometric techniques.

The data were processed using the Statistica 10.0 software package. The data obtained were presented as $M \pm S E M$. The significance of differences was determined with the help of non-parametric Mann-Whitney U-test and Wilcoxon test. Differences were considered statistically significant at $p<0.05$.

\section{Results}

The analysis of the clinical material carried out at the Toxicological Center of Municipal Hospital No.33 in order to determine the time of recovery from narcotic coma for the patients of various groups showed statistically significant reduction of this time in the group poisoned with the combination of various synthetic psychoactive substances and ethanol relative to the time of recovery from coma in the groups with poisoning by these substances introduced separately (Table 1).

The revealed paradoxical results of the combined effect of psychoactive substances and ethanol on the clinical picture and the state of the central nervous system in toxicological patients encouraged us to conduct an experimental study in order to find pathophysiological mechanisms of these effects using pharmaceutical preparations.

The results of studying behavioral reactions of the rats in the open field test under various kinds of acute intoxication are presented in Table 2.

After the recovery from coma, the distance that the imipramine animals walked when placed in the open field apparatus decreased almost 2 times relative to the control values and $12 \mathrm{~h}$ later the distance reduced by more than $50 \%$. A similar tendency was observed 
Table 1

Consciousness impairment duration and ethanol concentration in patients with monopoisoning by psychopharmacological preparations and their combination with ethanol (M $\pm S E M)$

\begin{tabular}{lccc}
\hline \multicolumn{1}{|c}{ Parameters } & $\begin{array}{c}\text { Synthetic psychoactive } \\
\text { substances }(n=67)\end{array}$ & $\begin{array}{c}\text { Ethanol } \\
(\mathrm{n}=54)\end{array}$ & $\begin{array}{c}\text { Synthetic psychoactive } \\
\text { substances and ethanol } \\
(\mathrm{n}=46)\end{array}$ \\
\hline Coma duration $(\mathrm{h})$ & $4.7 \pm 0.2$ & $5.3 \pm 0.3$ & $3.9 \pm 0.4^{*}$ \\
\hline Ethanol concentration in blood $(\%)$ & 0 & $3.7 \pm 1.7^{*}$ & $1.5 \pm 1.1^{*}$ \\
\hline
\end{tabular}

* Statistically significant differences of values with the group suffering from monopoisoning by psychopharmacological preparations, $\mathrm{p} \leq 0.05$.

Table 2

Rat behavior in the open field test under the influence of acute intoxication by psychopharmacological preparations,

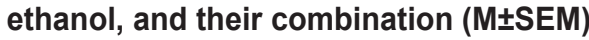

\begin{tabular}{|c|c|c|c|c|}
\hline Time of observation & $\begin{array}{l}\text { Group 1, physiological } \\
\text { solution (control) }(n=10)\end{array}$ & $\begin{array}{l}\text { Group 2, imipramine } \\
\qquad(n=10)\end{array}$ & $\begin{array}{l}\text { Group 3, ethanol } \\
\qquad(n=10)\end{array}$ & $\begin{array}{l}\text { Group 4, imipramine } \\
\text { in combination with ethanol } \\
(n=10)\end{array}$ \\
\hline $\begin{array}{l}\text { Horizontal activity } \\
\text { (the path travelled) (mm): } \\
\text { immediately after recovery from coma } \\
12 \mathrm{~h} \text { after recovery from coma }\end{array}$ & $\begin{array}{l}2054.0 \pm 96.6 \\
2054.0 \pm 96.6\end{array}$ & $\begin{array}{l}1052.8 \pm 18.5^{*} \\
494.2 \pm 8.2^{* \#}\end{array}$ & $\begin{array}{l}1523.6 \pm 21.7^{*} \\
883.7 \pm 5.1^{* \#}\end{array}$ & $\begin{array}{l}448.8 \pm 9.1^{*} \\
2020.2 \pm 2.0^{\#}\end{array}$ \\
\hline $\begin{array}{l}\text { Vertical activity (frequency of rearing/ } \\
5 \text { min): } \\
\text { immediately after recovery from coma } \\
12 \mathrm{~h} \text { after recovery from coma }\end{array}$ & $\begin{array}{l}8.91 \pm 1.07 \\
8.91 \pm 1.07\end{array}$ & $\begin{array}{l}3.67 \pm 0.83^{*} \\
0.17 \pm 0.11^{* \#}\end{array}$ & $\begin{array}{l}0.50 \pm 0.02^{*} \\
3.0 \pm 0.27^{\text {*\# }}\end{array}$ & $\begin{array}{c}0^{*} \\
5.17 \pm 0.91^{* \#}\end{array}$ \\
\hline $\begin{array}{l}\text { Grooming duration (s): } \\
\text { immediately after recovery from coma } \\
12 \mathrm{~h} \text { after recovery from coma }\end{array}$ & $\begin{array}{l}10.50 \pm 1.58 \\
10.50 \pm 1.58\end{array}$ & $\begin{array}{l}1.98 \pm 0.60^{*} \\
6.44 \pm 1.21^{* \#}\end{array}$ & $\begin{array}{c}8.86 \pm 1.34 \\
15.74 \pm 2.51^{\text {*\# }}\end{array}$ & $\begin{array}{c}1.37 \pm 0.34^{*} \\
13.40 \pm 2.25^{\#}\end{array}$ \\
\hline $\begin{array}{l}\text { Freezing duration (s): } \\
\text { immediately after recovery from coma } \\
12 \mathrm{~h} \text { after recovery from coma }\end{array}$ & $\begin{array}{l}0.48 \pm 1.17 \\
0.48 \pm 1.17\end{array}$ & $\begin{array}{c}80.81 \pm 30.3^{*} \\
122.31 \pm 22.11^{*}\end{array}$ & $\begin{array}{l}43.31 \pm 12.8^{*} \\
26.36 \pm 6.32^{*}\end{array}$ & $\begin{array}{l}175.64 \pm 8.96^{*} \\
3.23 \pm 0.82^{* \#}\end{array}$ \\
\hline
\end{tabular}

* Statistically significant differences in comparison with the control group; $p<0.05$, Mann-Whitney test; \# with the value "immediately after recovery from coma"; $p<0.05$, Wilcoxon test.

in animals after the recovery from alcoholic coma: twofold reduction in the level of the horizontal activity of the rats was noted in $12 \mathrm{~h}$ compared to the values of the control group. In the case of imipramine and ethanol combination, the distance traveled decreased by $76 \%$ in comparison with its initial values but already $12 \mathrm{~h}$ later it was restored to the control values.

Analyzing the frequency of rearings it was found that after the intraperitoneal injection of imipramine (group 2), this parameter decreased by $69 \%, 12 \mathrm{~h}$ later by $98 \%$ relative to the values of the control group. Group 3 (ethanol) was characterized by the decrease of this value after the recovery of the animals from coma by $\sim 95 \%, 12 \mathrm{~h}$ later some signs of restoration in the form of attempts to take a vertical position was noted, however, the frequency of rearing did not reach the level of the control group. In the rats with the combined introduction of the toxic agents (group 4) the frequency of rearing fell down to 0 after the recovery from coma. After $12 \mathrm{~h}$, there was observed a restoration of this parameter, which reached $58 \%$ of the control values.

Vegetative and emotional reactions, determined by the grooming time, in the experimental animals after the injection of psychotropic substance and its combination with alcohol (groups 2 and 4) were characterized by a significant reduction by 91 and $97 \%$, respectively, compared to the control values. In group 3 , significant changes were not revealed. It should be noted that $12 \mathrm{~h}$ after the recovery from coma, the duration of grooming increased in all experimental groups not reaching the control values in group 2, the highest possible values were found in ethanol group 3, and only in the combined action of imipramine and ethanol the results did not differ from the control.

When studying the duration of freezing reaction, protective inhibition associated with the intake of the 
Table 3

Activity of some enzymes in the rats $12 \mathrm{~h}$ after acute poisoning by imipramine and its combination with ethanol (MESEM)

\begin{tabular}{lccc}
\hline \multicolumn{1}{c}{ Enzymes } & $\begin{array}{c}\text { Physiological solution } \\
\text { (control) }(\mathrm{n}=10)\end{array}$ & $\begin{array}{c}\text { Imipramine } \\
(\mathrm{n}=10)\end{array}$ & $\begin{array}{c}\text { Imipramine } \\
\text { with ethanol }(\mathrm{n}=10)\end{array}$ \\
\hline Liver homogenate $(\mathrm{nmol}$ NADN/min.mg protein): & & & \\
EDG & $4.65 \pm 0.9$ & $2.33 \pm 0.21^{*}$ & $2.58 \pm 0.43^{*}$ \\
LDG & $11.6 \pm 1.35$ & $2.8 \pm 0.46^{*}$ & $3.1 \pm 0.69^{*}$ \\
\hline Erythrocyte hemolysate $(\mu \mathrm{mol} / \mathrm{min} \cdot \mathrm{mg} \mathrm{Hb}):$ & & & \\
SOD & $1.78 \pm 0.21$ & $0.64 \pm 0.09^{*}$ & $1.66 \pm 0.16^{* \#}$ \\
Catalase & $0.71 \pm 0.04$ & $0.18 \pm 0.02^{*}$ & $0.32 \pm 0.04^{*}$ \\
\hline
\end{tabular}

*Statistically significant differences in comparison with the control group, $p \leq 0.05$; \# among the experimental groups, $\mathrm{p} \leq 0.05$.

psychotropic substances, an excessive increase of the background indices in the animals after the recovery from coma was detected in all examined groups. However, $12 \mathrm{~h}$ later, the duration of immobilization in groups 2 and 3 remained at a high level relative to the control, while in group 4 , where imipramine was combined with ethanol, the values approximating to the background parameters were noted though they were statistically significantly higher.

The analysis of the orientation and exploratory behavior including a vegetative and emotional reaction of the animals after acute poisoning showed that $12 \mathrm{~h}$ after the recovery from coma in case of complex application of imipramine and ethanol, positive dynamics of restoration of the horizontal and vertical activity and reactions of grooming and freezing was observed. Thus, the results of the experiments confirmed the paradoxical clinical picture and the CNS condition in animals after poisoning by imipramine and ethanol.

The next stage of studying the effect of acute poisoning by the psychotropic substance and its combination with ethanol on the animals consisted in determining the activity of EDG and LDG in the rats liver and the antioxidant system enzymes in the erythrocyte hemolysate (SOD and catalase) (Table 3).

Ethanol dehydrogenase catalyzes alcohol oxidation and aldehydes reduction in the presence of coenzymes NAD and NADN. This is one of the key enzymes participating in alcohol metabolism in the body $[5,6]$.

$12 \mathrm{~h}$ after the recovery from coma induced by imipramine and its combination with ethanol, statistically significant decrease of EDG activity was found in the liver homogenate of the animals in comparison with the control values $(2.33 \pm 0.21 ; 2.58 \pm 0.43$ and $4.65 \pm 0.90 \mathrm{nmol} \mathrm{NADN} / \mathrm{min} \cdot \mathrm{mg}$ protein, respectively). However, significant differences among the experimental groups have not been established.

When determining LDG activity in the rat liver homogenates after acute poisoning, a similar tendency was detected. Statistically significant decrease of LDG activity was found in group 2 (imipramine) and group
3 (imipramine + ethanol) relative to the control values (group 1).

Taking into account the data about formation of the active forms of oxygen (AFO) $\left(\mathrm{O}_{2}^{-}, \mathrm{H}_{2} \mathrm{O}_{2}\right)$ when the activity of xenobiotic metabolizing enzymes is changing, including cytochrome systems P450, occurring in response to high concentrations of drugs in the organism, it is necessary to monitor the enzymes of antioxidant protection, i.e. SOD and catalase.

Intraperitoneal injection of imipramine results in 3-fold reduction of SOD activity compared to the control. Combined application of the toxicants decreases SOD activity only by $20 \%$. Statistically significant differences were found among the experimental groups, which is likely to be connected with the known alcohol property of being a trap for $\mathrm{OH}$-radicals [7].

When identifying catalase activity in the rat erythrocyte hemolysate, the enzyme activity diminished 4 times in group 2 relative to the control. In group 3, there was a 2-fold decrease of catalase activity compared to the control values, but it was statistically significantly higher than the values in group 2 .

Thus, the results of the investigations give evidence that the combination of imipramine with ethanol $12 \mathrm{~h}$ after the introduction aggravates intoxication of the organism by the level of the hepatic enzyme activity and antioxidant system state.

\section{Discussion}

The clinical data obtained intersect with the works [8] and [9] where it is noted that in patients taking ethanol with pharmacological preparations duration of consciousness and respiration impairment is significantly shorter. And this is explained by early remedial measures taken in response to the rapidly changing clinical picture of poisoning in the situations with combined intake of drugs and ethanol.

Our investigations were aimed at the evaluation of pathophysiological and biochemical mechanisms formed under the action of two toxicants. It has been 
confirmed experimentally that the locomotor activity after the recovery from coma is mostly inhibited by the combined ingestion of imipramine and ethanol, the introduction of imipramine alone is less inhibiting, and ethanol diminishes the distance travelled least of all. However, when imipramine and ethanol are consumed together, the distance is restored quicker than in other groups. It is the evidence of both the degree of brain cortex inhibition and the general organism tone, muscle strength, and endurance, i.e. general provision of the organism with energy.

Vertical activity, frequency of rearing on the hind legs (resting against the wall or not) is considered to be associated with the activity of both brain cortex and pons Varolii and mesencephalon responsible for maintaining the balance. In other words, the combined consumption of ethanol and imipramine affected the pons Varolii and mesencephalon (subcortical structures responsible for maintaining the balance) most intensively, but their functions are regenerated more rapidly.

Though there was a favorable restoration of the behavioral reactions in the combined administration of imipramine and ethanol, the analysis of detoxicating systems revealed multiple inhibition of enzyme activity in the liver. There is a close metabolic connection between the exchange of the substrates and products of ethanol dehydrogenase and lactate dehydrogenase reactions (ethanol-acetaldehyde and lactate/pyruvate) [10]. LDG as a glycolysis enzyme plays an important role in the regulation of the cell energy exchange. Therefore, a diminished enzymatic activity allows us to speak about energy exhaustion in all experimental groups.

The mechanism of catalytic hydroxylation of cytochrome P450 substrates is complicated, includes several stages, and is accompanied by the generation of AFO (superoxide anion radical, hydrosuperoxide, hydroperoxide) which are formed due to incomplete coupling, i.e. inadequacy of the reaction cycle stoichiometry [11].

The negative effect of ethanol combined with imipramine was demonstrated by Tanaka in the experiment with the human liver microsomes [12].

Antioxidant system enzymes are referred to the protective mechanisms in cases of acute poisoning. SOD is one of the main enzymes of this system catalyzing the reaction of dismutation of superoxide anion radicals maintaining their concentration in the cell at a low level. SOD also plays a role in the decrease of the probability of generating a more active form of singlet oxygen. Hydrogen peroxide generated as a result of dismutation is inactivated by catalase with water formation. The reduction of enzyme activity may be caused by the overload on the antioxidant system exposed to the alcohol and psychotropic agent. Enzyme depletion results in the growth of potential oxidant pool generated in the course of incomplete degradation of imipramine and ethanol.
The ambiguous effect of maintaining enzyme activity of the antioxidant system under the combined influence of both toxicants, probably, owing to the energy capacity of the ethanol molecule requires close attention and further exploration.

Thus, the combined effect of imipramine and ethanol inhibits more intensively neurophysiological functions of the organism but vanishes more rapidly as well. This is not referred to subcortical structures, which are regenerated longer due to ethanol action. In other words, ethanol mainly affects subcortical structures while imipramine the brain cortex. Extrapolating the obtained data to the clinical picture of the patients being too early discharged from the hospital after poisoning by combined psychotropic substances, it should be kept in mind that though the activity of the brain cortex is regenerated quickly enough, subcortical structures remain impaired for some time representing latent hazard to them. Patients with combined poisoning by imipramine and ethanol require prolong inpatient observation and outpatient follow-up in spite of evident improvements in their clinical picture.

\section{Conclusion}

In acute poisoning by imipramine and ethanol, restoration of orientation and exploratory behavior of animals occurs more rapidly, inhibition of enzymatic activity of the liver (ethanol dehydrogenase, lactate dehydrogenase) and the antioxidant system (catalase and superoxide dismutase) are observed but to the less extent than in acute imipramine intoxication.

Study funding. The work was not supported by any financial source.

Conflicts of interest. The authors have no conflicts of interest to declare.

\section{References}

1. Yatsinyuk B.B., Volkova N.A., Salmanov Yu.M., Fomin I.V. Clinic, diagnosis of acute poisoning with synthetic cannabinoids and features of pathogenetic therapy of victims. Zdravookhranenie Yugry: opyt i innovatsii 2016; 1: 28-44.

2. Toybaeva G.M., Dzharkimbekova G.K., Akhmetova B.U., Cheglakova V.M. Combined poisoning of ethyl alcohol and drugs. Vestnik Kazakhskogo natsional'nogo meditsinskogo universiteta 2015; 1: 291-292.

3. Dzharkinbekova G.K. Neuropsychiatric disorders in acute poisoning by psychotropic drugs. Vestnik Kazakhskogo natsional'nogo meditsinskogo universiteta 2014; 4: 107-109.

4. Larchenko A.V., Suvorov M.A., Andryukhin V.I., Kaurov Ya.V., Suvorov A.V. Synthetic cathinones and cannabinoids are new psychoactive substances (review). Sovremennye tehnologii $v$ medicine 2017; 9(1): 185-197, https://doi.org/10.17691/stm2017.9.1.23.

5. Zakhari S. Overview: how is alcohol metabolized by the body? Alcohol Res Health 2006; 29(4): 245-254.

6. Mukherjee S. Alcohol metabolism and generation of free radicals: a deep insight. OA Alcohol 2014; 2(1): 10. 
7. Narkologiya: natsional'noe rukovodstvo [Narcology: national leadership]. Pod red. Ivantsa N.N., Anokhinoy I.P., Vinnikovoy M.A. [Ivanets N.N., Anokhina I.P., Vinnikova M.A. (editors)]. Moscow: GEOTAR-Media; 2008.

8. Ilyashenko K.K., Luzhnikov Ye.A., Kareva M.V., Rozhkov P.G., Kashtanova I.S., Lisovik Zh.A., Elkov A.N. Specificitics of acute poisonings by Carbamazepinum at different ways of its use. Toksikologicheskiy vestnik 2010; 6: 2-5.

9. Zobnin Y.V., Stadler E.M. Acute poisoning with synthetic cannabinoids ("spice"). Sibirskiy meditsinskiy zhurnal (Irkutsk) 2014; 8: 130-135.

10. Pronko P.S., Satanovskaya V.I., Gorenstein B.I., Kuzmich A.B., Pyzhik T.N. Effect of pyruvate, threonine and phosphoethanolamine on blood endogenous acetaldehyde metabolism in rats with toxic liver injury. Voprosy meditsinskoy khimii 2002; 3: 278-285.

11. Xu J., Ma H.Y., Liang S., Sun M., Karin G., Koyama Y., Hu R., Quehenberger O., Davidson N.O., Dennis E.A., Kisseleva T., Brenner D.A. The role of human cytochrome P450 2E1 in liver inflammation and fibrosis. Hepatol Commun 2017; 1(10): 1043-1057, https://doi.org/10.1002/hep4.1115.

12. Tanaka E., Nakamura T., Terada M., Honda K. An in vitro study on the interaction between ethanol and imipramine at high concentrations using human liver microsomes. Forensic Toxicology 2007; 25(2): 96-99, https://doi.org/10.1007/s11419007-0036-4. 